The double-chambered right ventricle is a developmental cardiac anomaly in which aberrant muscular bands obstruct the body of the right ventricle dividing it into a high-pressure proximal chamber and a low-pressure distal chamber. Grant, Downey, and MacMahon (1961) considered that the obstruction, which is situated at the start of the outflow tract adjacent to the moderator band, is caused by hypertrophy of the oblique component of the bulbar musculature. Associated congenital cardiac abnormalities have been found in $\mathbf{4 0}$ of $\mathbf{5 2}$ reported cases (Grant et al., 1961; Tsifutis, Hartmann, and Arvidsson, 1961; Lucas et al., 1962; Hartmann et al., 1962; Coates, McClenathan, and Scott, 1964; Hartmann, Goldring, and Carlsson, 1964; Schlesinger, van Randwijk, and Chaillet, 1965; Warden, Lucas, and Varco, 1966; Girod et al., 1966; Hindle, Engle, and Hagstrom, 1968; Lintermans et al., 1968). Of these, 28 were ventricular septal defects; others were pulmonary valvular stenosis, pulmonary atresia, and patent ductus arteriosus.

Pure infundibular stenosis of the right ventricle was described by Keith in 1909. Brock (1957), in his monograph on pulmonary stenosis, did not distinguish a separate entity of double-chambered right ventricle but regarded it as a variant of infundibular stenosis in which the muscular obstruction was unusually low ("subdivision of the right ventricle"). Other authors (Grant et al., 1961; Lucas et al., 1962; Perloff, Ronan, and de Leon, 1965) considered that the double-chambered right ventricle was a separate embryological entity and emphasized that the obstruction was caused by aberrant bands of muscle. The fact that an associated ventricular septal defect may communicate with either the distal or the proximal chamber has been taken to support this hypothesis

Received July 9, 1968.
(Lucas et al., 1962; Hartmann et al., 1962;

Schlesinger et al., 1965).

Irrespective of the correct interpretation, a preoperative diagnosis of the condition is of importance. Anatomical relationships may be difficult to define at operation, and Lucas et al. (1962) described 2 unrecognized cases of double-chambered right ventricle in which inadvertent closure of the transventricular channel, which in both instances had been mistaken for a ventricular septal defect, had a fatal outcome. The origins of the muscle bundles from the upper part of the interventricular septum often obscure the ventricular septal defect, and our surgeons have experienced difficulty in ascertaining whether the defect opened into the proximal or the distal chamber. The tricuspid valve is also hidden, and damage to the valve mechanism by interference with the papillary muscles during resection of aberrant bundles is another hazard (Brock, 1957; Coates et al., 1964). Difficulties in assessing the precise anatomy of the malformation at open heart operation are further indicated by the reported cases (Lucas et al., 1962; Schlesinger et al., 1965) in which the true diagnosis was made only after operation had failed to abolish or diminish the signs of right ventricular outflow obstruction. An incorrect diagnosis of Fallot's tetralogy led to 2 shunt operations in a patient (Perloff et al., 1965) in whom the muscular hypertrophy was so pronounced that complete obstruction eventually supervened.

Nearly all the reported cases of double-chambered right ventricle were diagnosed only at operation or necropsy. In this paper an attempt is made to define the clinical, electrocardiographic, and cardiac catheterization features of the condition, based on an experience of 5 patients. The patients were encountered over a $2 \frac{1}{2}$-year period during which a total of 310 new cases of congenital heart disease was seen at this clinic. 
TABLE I

CLINICAL AND OPERATIVE FINDINGS

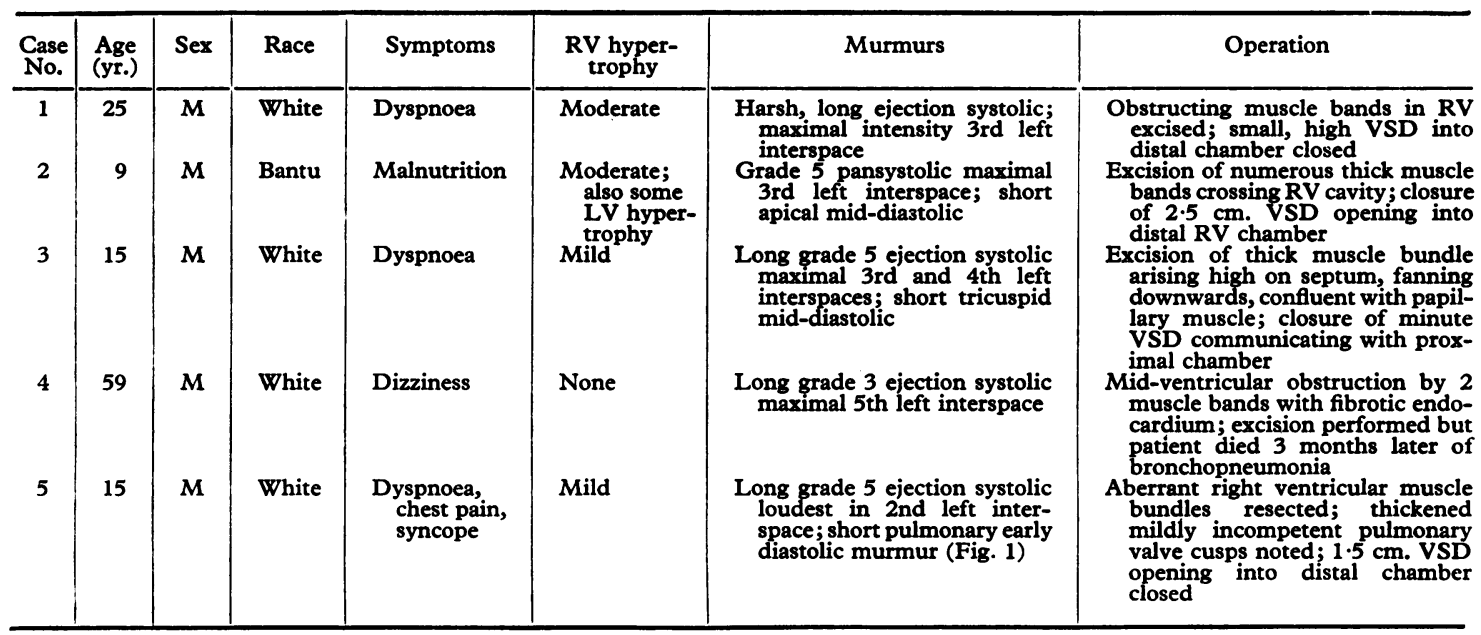

$R V=$ right ventricle; $L V=$ left ventricle; $V S D=$ ventricular septal defect.

\section{Clinical Features}

All the patients were male; their ages ranged between 9 and 59 years (Table I). Symptoms consisted mainly of fatigue and dyspnoea. Each of 4 patients had a long, loud ejection systolic murmur (Fig. 1), suggestive of considerable right ventricular outflow obstruction, whereas palpation of the praecordium indicated only mild or moderate right ventricular hypertrophy. The pulmonary component of the second sound $\left(\mathbf{P}_{2}\right)$ was generally not as soft or as delayed as would be expected from the length of the murmur in a case of pulmonary stenosis. The murmur was pansystolic in 1 patient (Case 2) who had a moderate-sized ventricular septal defect. Three others (Cases 1, 3, and 5, Table I) also had ventricular septal defects. One patient (Case 3) had a mid-diastolic tricuspid murmur suggestive of right ventricular inflow obstruction. The first patient encountered (Case 1) was correctly diagnosed only after operation, but in all subsequent cases the condition was recognized, or strongly suspected, on clinical and electrocardiographic features before cardiac catheterization.

\section{EleCtrocardiographic Features}

In all cases the appearance of at least one limb lead is out of context with the general pattern of the mean frontal plane QRS axis. Thus, there is a lack of expected positivity of the QRS complex towards the positive pole of lead AVR, and this may be noted in other leads as well as in AVR (Fig. 2).
This phenomenon may be attributed to the lack of muscle mass in the distal chamber of the right ventricle. The praecordial leads may also reveal features that suggest an hypertrophied but localized muscle mass. Thus, a dominant $R$ wave in lead V4R is a striking feature, whereas the $R$ wave is smaller or an rS complex occurs in V1. In fact, the praecordial leads without V4R show no conclusive evidence of right ventricular hypertrophy, and $S$ waves are inconspicuous or absent in the left praecordial leads.

\section{RADIOGRAPHIC FEATURES}

$X$-ray examination revealed no characteristic features and was generally not of great diagnostic aid, but pulmonary plethora in the presence of right ventricular outflow obstruction occurred in Case 2. The usual appearances were of mild right ventricular and right atrial enlargement. The pulmonary artery was dilated in Case 4, and this was presumably attributable to associated fibrosis of the valve cusps. Diminution in the vascular markings at the right base in Case 5 was later shown angiographically to have resulted from occlusion or stenosis of a branch of the right pulmonary artery.

\section{Cardiac Catheterization AND ANGIOCARDIOGRAPHY}

All patients were catheterized (Table II) and in 2 the studies were repeated after surgical correction. A hydrogen inhalation technique (Heimann and 


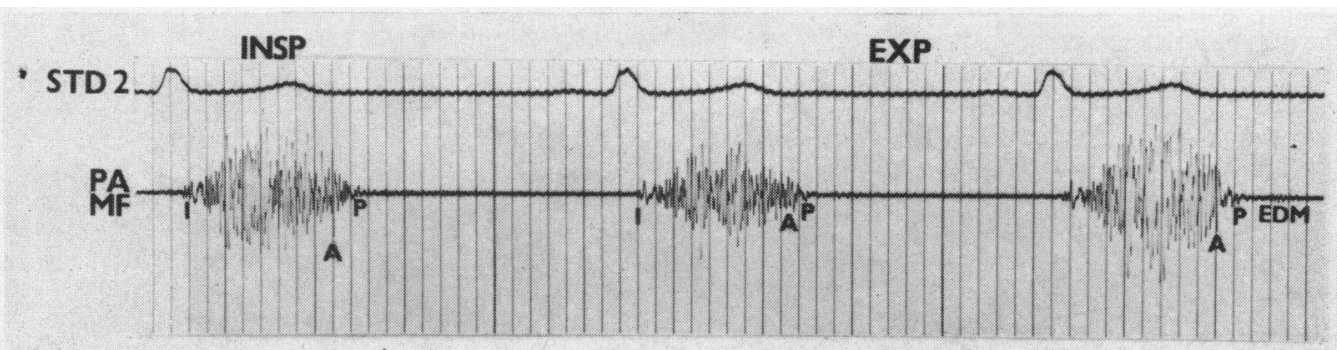

FIG. 1.-Phonocardiogram, Case 5. A long, loud pulmonary ejection murmur extends past aortic valve closure (A). The pulmonary component of the second sound $(P)$ is soft and follows $A$ by 0.06 sec. in inspiration and $0.04 \mathrm{sec}$. in expiration. The pulmonary early diastolic murmur (EDM) has recorded faintly. Time intervals $=0.04 \mathrm{sec}$.

Barlow, 1965) was used to detect a left-to-right shunt, and the size of the shunt was then estimated by oximetry. Intraventricular systolic pressure gradients ranging from 25 to $135 \mathrm{~mm}$. $\mathrm{Hg}$ were demonstrated (Table II and Fig. 3). The characteristic angiocardiographic appearance in all cases was one of a coarsely trabeculated inflow, or proximal, chamber of the right ventricle, which was separated by filling defects representing muscle bundles from a smooth-walled outflow, or distal, chamber (Fig. 4 and 5).

Case 5 illustrates a pitfall in the catheter diagnosis of the condition. In this patient, gradients were present at 2 levels in the right ventricle (Fig. 3b), but the catheter tip appeared, during 3 consecutive withdrawals from pulmonary artery to right atrium, to be at the valvular and the immediate subvalvular ("infundibular") levels, respectively, when the gradients were recorded. These findings suggested a diagnosis of combined valvular and infundibular pulmonary stenosis, but the correct diagnosis, later confirmed at operation, was revealed by angiography which demonstrated a coarsely trabeculated lower chamber, a smooth-walled distal chamber, and, in addition, a narrow infundibular area (Fig. 5). The maximal right ventricular pressure was recorded on 3 occasions when the catheter tip, viewed in the usual postero-anterior projection, was just below the pulmonary valve and apparently in a position where, judged from the angiocardiogram in the postero-anterior projection, the low pressure smooth-walled distal portion of the right ventricle should have been. We believe that the catheter must have been in the proximal chamber but lying in a posterior plane behind the high septal insertion of an aberrant muscle bundle. The anomaly may thus be missed at cardiac catheterization if reliance is placed on pressure gradients alone.

\section{OPERATION}

The obstruction was relieved by operation in all patients, and excellent results, with relief of symptoms, were achieved in 4 (Table I). The remaining patient (Case 4) developed sternal sepsis and cerebral vascular insufficiency, and died of bronchopneumonia 3 months after operation.

TABLE II

CATHETERIZATION DATA

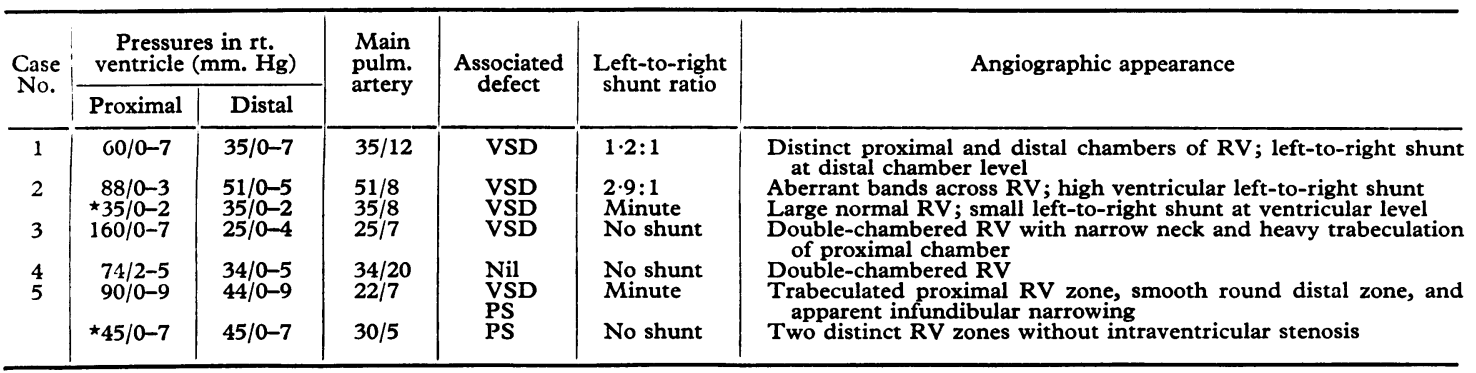

PS = pulmonary stenosis.

$\star$ Post-operative results. 


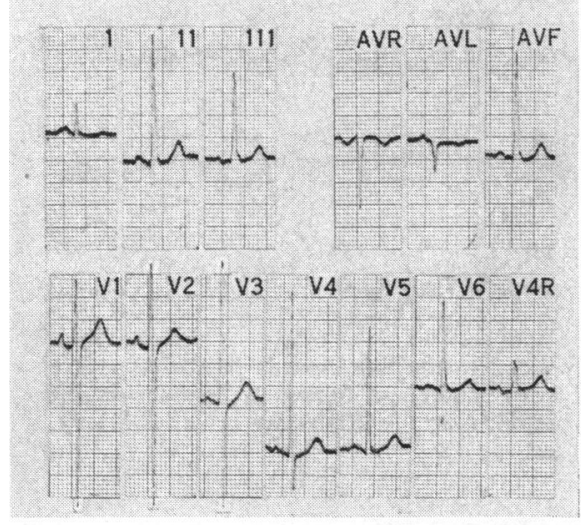

(a)

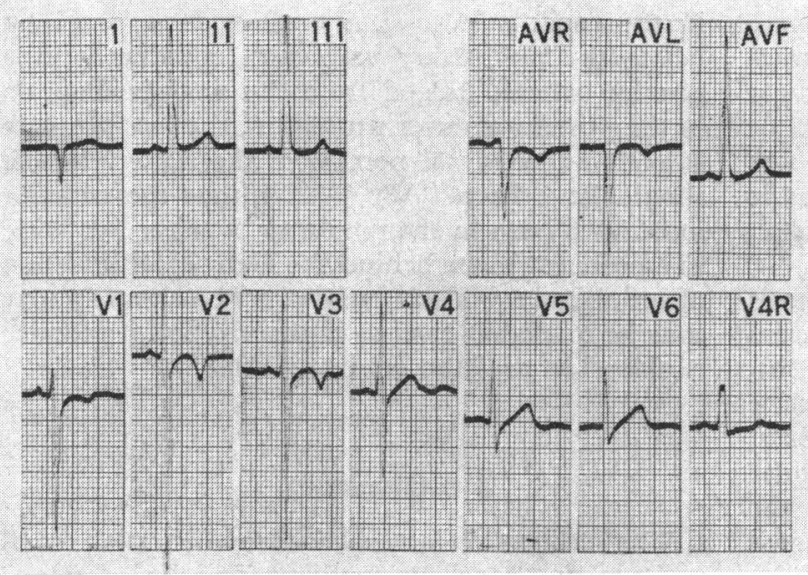

(c)

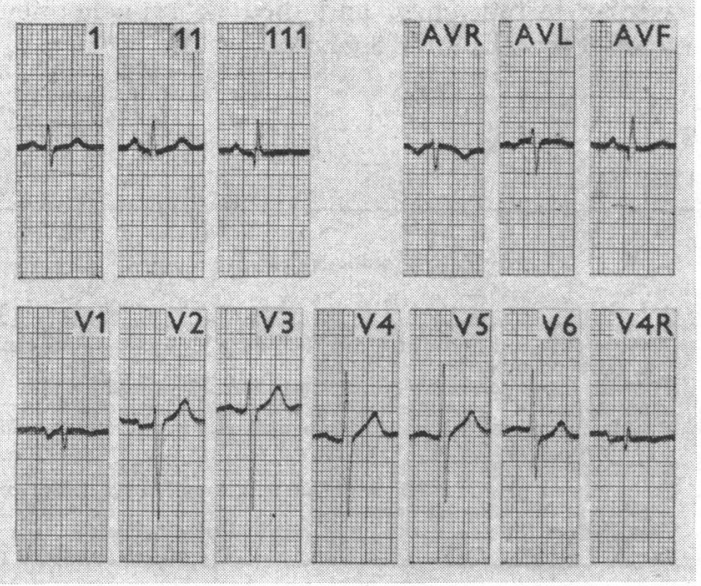

(d)

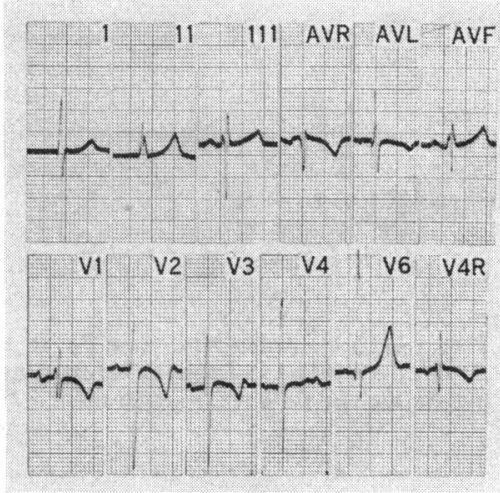

(b)

Fig. 2.-(a-e) Electrocardiograms of Cases 1-5, respectively. Despite mean frontal plane QRS axes of $120^{\circ}$, Cases 3 and 5 have no $R$ wave in lead AVR. In Case 4, where the QRS axis is $+80^{\circ}$, the $R$ wave in lead AVR is also much smaller than would be expected. Case 1 apparently has a QRS axis of $+80^{\circ}$ yet no $S$ wave in lead $I$ and similarly Case 2 lacks an $S$ in lead II, though other leads indicate that the QRS axis is about $-5^{\circ}$. Cases 1,3 , and 5 show dominant $R$ waves in lead V4R and a much smaller $r$ in lead V1. Note also the deep $S$ waves in the right chest leads. These unusual appearances may be accounted for by the localized hypertrophy of the right ventricle. (See text.) 


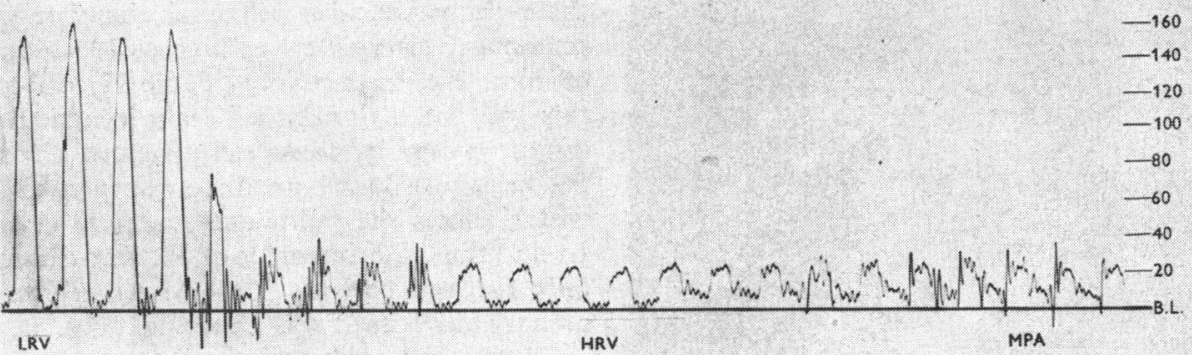

(a)

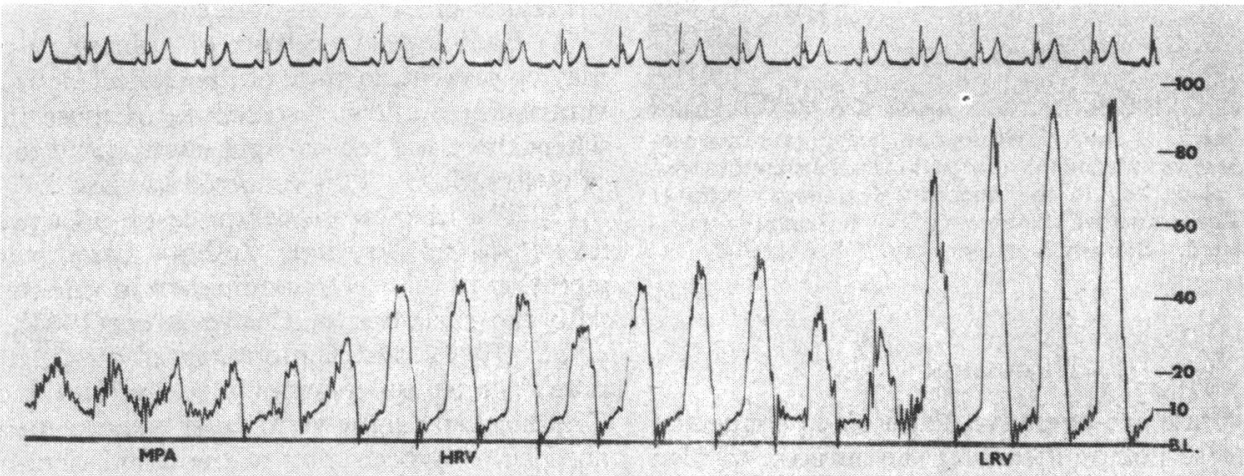

(b)

FIg. 3.-(a) Case 3. Pressure tracing showing a systolic gradient of $135 \mathrm{~mm}$. Hg between proximal (LRV) and distal (HRV) chambers of the right ventricle. MPA = main pulmonary artery, B.L.= baseline. (b) Case 5, withdrawal pressure tracing. Subvalvular and intraventricular gradients are recorded. (See text.)

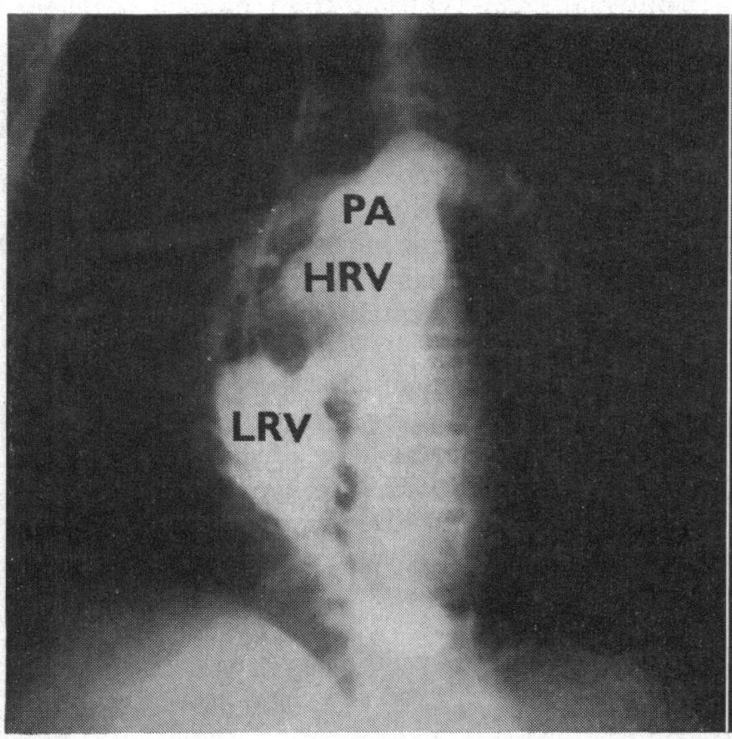

(a)

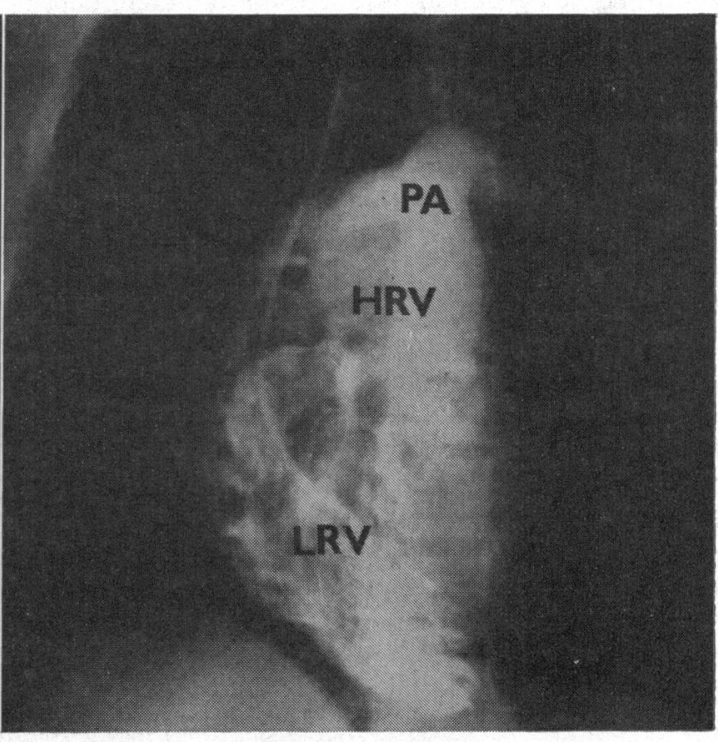

(b

FIG. 4.-Case 3, angiocardiograms, $15^{\circ}$ left anterior oblique projection. (a) Systole. (b) Diastole. The right ventricle is divided into a lower or proximal trabeculated zone (LRV) and a high or distal smooth-walled zone (HRV) by muscle bands seen as filling defects. $P A=$ pulmonary artery. 


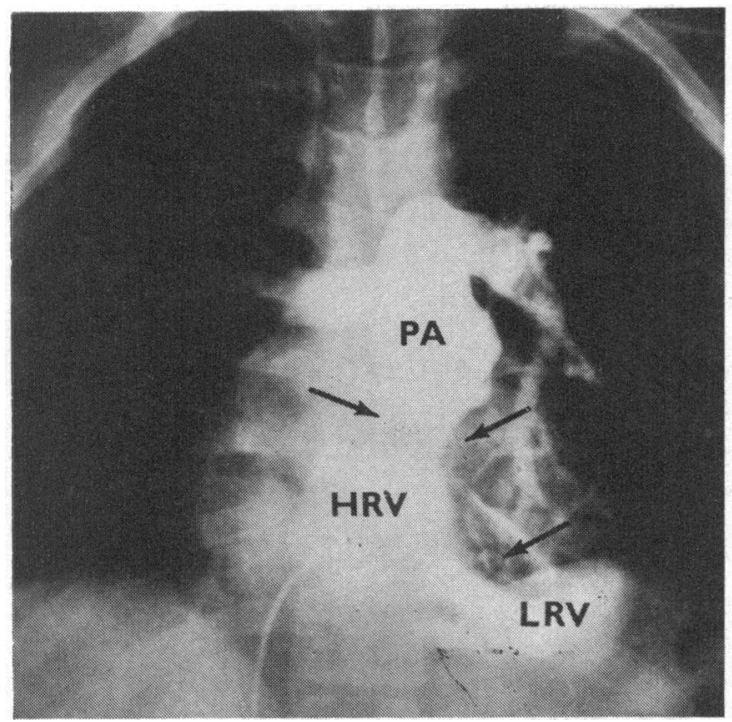

Fig. 5.-Case 5. Right ventriculogram, postero-anterior projection. Arrows indicate the obstructing muscle bundles running in a plane behind the smooth-walled distal chamber (HRV). The proximal chamber (LRV) is coarsely trabeculated. PA = pulmonary artery. (See text.)

\section{Discussion}

An accurate pre-operative diagnosis in congenital heart disease not only enables the surgeon to plan an operation correctly, but also contributes to his precise understanding of the anatomical and functional features of the case. With complex anomalies, difficulties in accurate assessment may be encountered at operation, and the double-chambered right ventricle has been responsible for serious errors in the past. Previous reports have seldom emphasized the importance of the pre-operative recognition of this potentially curable condition. Valuable diagnostic signs are as follows.

(1) The ejection systolic murmur, which is characteristically loud and long, is of maximal intensity in the third or even fourth left interspace (Watden et al., 1966). The site of the thrill, if present, is therefore also low.

(2) The pulmonary valve closure sound may not be as delayed or as soft as would be expected from the length of the murmur if the obstruction were at infundibular or valvular level. In such instances, the A2 (aortic closure)-P2 interval and the intensity of P2 have been correlated with the right ventricular systolic pressure and the length of the right-sided ejection murmur (Leatham and Weitzman, 1957; Auerback and Sokolow, 1959; Vogelpoel and Schrire, 1960; Barlow and Pocock, 1965). In 2 of our patients (Cases 3 and 5) the A2-P2 interval, recorded phonocardiographically during natural expiration, was only 0.05 and 0.04 sec., respectively, whereas the systolic pressure differences between the right ventricular proximal chamber and main pulmonary artery were as high as $135 \mathrm{~mm} . \mathrm{Hg}$ and $68 \mathrm{~mm}$. Hg, respectively (Table II). Reasons for this may be a diminished right ventricular stroke output caused by the small proximal chamber and the relatively low immediate subvalvular pressure which allows the pulmonary valve to close earlier. In addition, the intensity of $\mathbf{P 2}$ was diminished in only 1 of our patients (Case 5)-in whom the pulmonary valve itself was abnormal (Fig. 1).

(3) Clinical evidence of right ventricular hypertrophy may appear less than would be expected from the degree of outflow obstruction as judged by the length of the ejection murmur.

(4) Radiological evidence of pulmonary plethora may be present, in spite of the clinical signs of right ventricular outflow obstruction, in those instances where there is a left-to-right shunt distal to the site of obstruction. This occurred in Case 2.

(5) The electrocardiogram is of principal diagnostic value. Previous authors have paid little attention to the electrocardiogram in this condition, with the exception of Coates et al. (1964), Perloff et al. (1965), and Lintermans et al. (1968), who noted similar appearances in 3 of a total of 6 cases. The localized right ventricular muscle mass, with absence of hypertrophy of the distal chamber, has been invoked to explain these electrocardiographic features on a vectorial basis (Coates et al., 1964).

On these criteria it should be possible, even before cardiac catheterization, to distinguish a doublechambered right ventricle from Fallot's tetralogy, isolated pulmonary stenosis, lone ventricular septal defect, or pulmonary stenosis with an associated ventricular septal defect shunting left to right. The anomaly may also simulate idiopathic hypertrophic obstructive cardiomyopathy predominantly affecting the right side of the heart. In our experience of this latter entity (Tucker et al., 1966), however, there is invariably an associated left ventricular outflow obstruction or left ventricular distortion on cineangiocardiography.

The demonstration at catheterization of a systolic pressure gradient in the right ventricle which is proximal to the usual site of infundibular obstruction, together with the typical angiographic appearance of two chambers, confirms the diagnosis. The proximal high pressure zone may be missed if it is not specifically sought by probing towards the apex of the ventricle. Thus, with a conventional withdrawal from the pulmonary artery, the catheter may appear to flick from the distal part of the right 
ventricle directly into the right atrium. This can occur because of the close anatomical relation between the aberrant muscle bundles and the tricuspid valve (Brock, 1957; Hartmann et al., 1962; Warden et al., 1966). Conversely, as happened in Case 5, the distal low pressure zone may be missed if the catheter tip, on withdrawal from the pulmonary artery, slips behind a muscle bundle to lie high in the proximal chamber. With the catheter in this position, and viewed in the conventional posteroanterior projection, a high pressure may be misinterpreted as being in the distal part of the right ventricle, and thus an incorrect diagnosis of valvular or infundibular stenosis made. The angiocardiogram is then essential to establish the diagnosis. Finally, an intraventricular gradient may be absent if the obstruction is mild (Lucas et al., 1962; Warden et al., 1966; Hindle et al., 1968; Lintermans et al., 1968). In such instances, the development of a gradient over a period of years has been observed (Hartmann et al., 1964).

The tricuspid mid-diastolic murmur in Case 3 suggested right ventricular inflow obstruction, though no diastolic gradient could be shown across the tricuspid valve. Inflow obstruction has been noted by other authors (Girod et al., 1966).

Our experience confirms the observation of others (Tsifutis et al., 1961; Lucas et al., 1962; Hartmann et al., 1962) that an associated ventricular septal defect may communicate with either right ventricular chamber. It is noteworthy that in Case 1 neither oximetry nor hydrogen inhalation demonstrated mixing of shunted blood between the distal and proximal chambers. The small right-to-left shunt which must have been present in Case 3 was not seen on angiography and the arterial oxygen saturation was not estimated.

Features of the double-chambered right ventricle that may be apparent at operation include a dimpling or a grooving of the right ventricular surface, a systolic thrill over the outflow tract of the right ventricle rather than over the pulmonary artery, and difficulty in identifying the tricuspid valve after the right ventricle has been opened (Warden et al., 1966). If the diagnosis is missed at operation, signs of right ventricular outflow obstruction will persist after completion of "corrective" surgery (Lucas et al., 1962).

The nature of the stimulus to hypertrophy of portions of the right ventricle is not always clear, and it is particularly difficult to understand in those instances in which a gradient is initially absent. The resected myocardium in Case 3 bore no histochemical resemblance to that seen in hypertrophic obstructive cardiomyopathy (Pearse, 1964), in that the glycogen, noradrenaline, diphosphopyridine nucleotide diphorase, monoamine oxidase, and nonspecific esterase contents were all normal.

\section{SUMMARY}

The clinical, electrocardiographic, cardiac catheterization, and other features of 5 cases of doublechambered right ventricle are presented. In each instance the diagnosis was confirmed at operation. Diagnostic criteria are discussed. Notable electrocardiographic features include an appearance of at least one limb lead out of context with the general pattern of the mean frontal plane QRS axis and a dominant $R$ in lead V4R, whereas an $r S$ complex appears in lead V1. These electrocardiographic abnormalities are attributed to the absence of hypertrophy of the distal right ventricular chamber. Surgical pitfalls are stressed, which emphasize the necessity for pre-operative diagnosis of this potentially fatal condition.

We wish to thank our thoracic surgical colleagues, Mr. P. Marchand, Mr. L. A. du Plessis, and Mr. G. Katz, for their co-operation. The late Professor B. J. P. Becker performed the histochemistry in Case 3. We are also indebted to Mrs. C. K. Bosman and Miss P. A. Palfrey for technical assistance. We are grateful to Dr. H. van Wyk, Superintendent of the Johannesburg Hospital, for permission to publish.

\section{REFERENCES}

Auerback, M. L., and Sokolow, M. (1959). Phonocardiography in acyanotic congenital heart disease. Pediatrics, 24, 1026.

Barlow, J. B., and Pocock, W. A. (1965). The isolated systolic murmur. S. Afr. med. F., 39, 909.

Brock, R. (1957). The Anatomy of Congenital Pulmonary Stenosis. Cassell, London.

Coates, J. R., McClenathan, J. E., and Scott, L. P. (1964). The double-chambered right ventricle. A diagnostic and operative pitfall. Amer. F. Cardiol., 14, 561.

Girod, D. A., Raghib, G., Adams, P., Jr., Anderson, R. C., Wang, Y., and Edwards, J. E. (1966). Cardiac malformations associated with ventricular septal defect. Amer. F. Cardiol., 17, 73.

Grant, R. P., Downey, F. M., and MacMahon, H. (1961). The architecture of the right ventricular outflow tract in the normal human heart and in the presence of ventricular septal defects. Circulation, 24, 223.

Hartmann, A. F., Jr., Goldring, D., and Carlsson, E. (1964). Development of right ventricular obstruction by aberrant muscular bands. Circulation, 30, 679.

- Tsifutis, A. A., Arvidsson, H., and Goldring, D. (1962). The two-chambered right ventricle. Report of nine cases. Circulation, 26, 279.

Heimann, K. W., and Barlow, J. B. (1965). The use of hydrogen inhalation in the detection of intracardiac shunts. S. Afr. med. F., 39, 952.

Hindle, W. V., Jr., Engle, M. A., and Hagstrom, J. W. C. (1968). Anomalous right ventricular muscles. A clinicopathologic study. Amer. F. Cardiol., 21, 487.

Keith, A. (1909), Malformations of the heart. Lancet, 2, 359. 
Leatham, A., and Weitzman, D. (1957). Auscultatory and . phonocardiographic signs of pulmonary stenosis. Brit. Heart f., 19, 303.

Lintermans, J. P., Roberts, D. B., Guntheroth, W. G., and Figley, M. M. (1968). Two-chambered right ventricle without outflow obstruction in ventricular septal defect. A case of spontaneous correction. Amer. F. Cardiol., 21, 582 .

Lucas, R. V., Jr., Varco, R. L., Lillehei, C. W., Adams, P., Jr., Anderson, R. C., and Edwards, J. E. (1962). Anomalous muscle bundle of the right ventricle. Hemodynamic consequences and surgical considerations. Circulation, 25, 443.

Pearse, A. G. E. (1964). The histochemistry and electron microscopy of obstructive cardiomyopathy. In Ciba Foundation Symposium: Cardiomyopathies, p. 132. Ed. by G. E. W. Wolstenholme and M. O'Connor. J. and A. Churchill, London.

Perloff, J. K., Ronan, J. A., Jr., and de Leon, A. C. (1965). Ventricular septal defect with the "two-chambered right ventricle". Amer. F. Cardiol., 16, 894.
Schlesinger, F. G., van Randwijk, J., and Chaillet, J. L. (1965). Two-chambered right ventricle with interventricular septal defect. Cardiologia (Basel), 47, 256.

Tsifutis, A. A., Hartmann, A. F., Jr., and Arvidsson, H. (1961). Two-chambered right ventricle: report on seven patients. (Abstr.) Circulation, 24, 1058.

Tucker, R. B. K., Barlow, J. B., Zion, M. M., and Gale, G. E. (1966). Hypertrophic obstructive cardiomyopathy in Johannesburg. A study of 90 patients. Paper presented at the Fifth Biennial Congress of the Southern Africa Cardiac Society, Stellenbosch, October 1966, and at the Fifth World Congress of Cardiology, New Delhi, November 1966.

Vogelpoel, L., and Schrire, V. (1960). Auscultatory and phonocardiographic assessment of pulmonary stenosis with intact ventricular septum. Circulation, 22, 55.

Warden, H. E., Lucas, R. V., Jr., and Varco, R. L. (1966). Right ventricular obstruction resulting from anomalous muscle bundles. f. thorac. cardiovasc. Surg., 51, 53. 